\title{
A Cost-effective DNA Isolation Strategy from Crustaceans Enables the First Molecular Phylogenetic Identification of Moina macrocopa from India
}

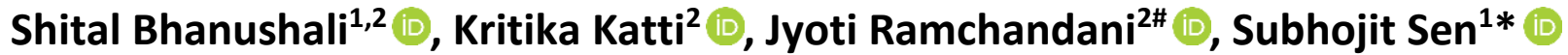 \\ ${ }^{1}$ Mumbai University, School of Biological Sciences, UM-DAE Centre for Excellence in Basic Sciences, Kalina Campus, \\ Santacruz (E), Mumbai 400098. \\ ${ }^{2}$ University of Mumbai, Department of Life Sciences, Vidyanagari, Santacruz (E), Mumbai 400098. \\ *Corresponding Author \\ ${ }^{\#}$ Co-corresponding Author
}

\section{How to cite}

Bhanushali, S., Katti, K., Ramchandani, J., Sen, S. (2021). A Cost-effective DNA Isolation Strategy from Crustaceans Enables the First Molecular Phylogenetic Identification of Moina macrocopa from India. Genetics of Aquatic Organisms 5(2), 77-85. http://doi.org/10.4194/2459-1831-v5_2_04

\section{Article History}

Received 13 January 2021

Accepted 03 June 2021

First Online 21 June 2021

\section{Corresponding Author}

Tel.: +919820580794

$+919029602082$

E-mail: subhojit.sen@cbs.ac.in jyoti.r@lifesciences.mu.ac.in

\section{Keywords}

Porcelain abrasion

Barcoding

Nucleic acid extraction

Water flea

\begin{abstract}
We report the first barcode identification of water flea species Moina macrocopa (strain JSK1) from the Indian subcontinent. The strain isolated from a freshwater pond near Mumbai by collective efforts of CUBE (Collaborative Undergraduate Biology Education), was morphologically characterized as Moina species. Keeping up with the growing demand of affordable science in colleges and to avoid hazardous technologies, we established a home grown porcelain-abrasion DNA extraction strategy for crustaceans, and compared it against routinely used protocols employing liquid nitrogen or insect-DNA isolation kits. Our method successfully yielded high quality genomic DNA from Moina, comparable to published protocols as further analysed by restriction digestion, ligation and PCR efficiency. We also sequenced two barcoding loci namely, $\mathrm{COI}$ and ITS sequences, duly submitted and curated by Genbank (accession numbers MH734122.1 and MH745035.1). Molecular phylogenetic analyses identified the Indian species as Moina macrocopa and related it closely to the Russian clade. Protein prediction analyses of the variations in $\mathrm{COI}$ revealed that the missense mutations lie in the aliphatic membrane helices and should not affect the catalytic capacity of cytochrome oxidase. The strain JSK1 is currently disseminated and maintained collectively by CUBE students across India, towards developing it as a model system.
\end{abstract}

\section{Introduction}

Daphnia and Moina, commonly known as 'water fleas' are members of the order Cladocera, class Crustacea and the phylum Arthropoda. Commonly found in freshwater habitats, these filter feeders are economically important both as live feed in aquaculture (Mandal \& Bhagabati, 2012) as well as model organisms for eco-toxicological assays, environmental genomics, toxicogenomics, and epigenetics studies (Athanasio, Chipman, Viant, \& Mirbahai, 2016).
Although still widely employed for Moina (Padhye \& Dumont, 2014), the morphological identification system has significant limitations because phenotypic plasticity and genetic variability may lead to difficulty in differentiating between morphologically cryptic taxa and therefore lead to incorrect identification of species. In addition, morphological keys are often restrictive for a particular life-stage or gender and often demands a high level of expertise, making misdiagnoses a real possibility (Hebert et al., 2003). These limitations can be overcome by using a micro-genomic identification 
system which exploits specific sequences of genomic DNA as molecular barcodes (Pentinsaari, Salmela, Mutanen, \& Roslin, 2016). In 2003, a fragment of mitochondrial Cytochrome $\mathrm{C}$ oxidase subunit I (COI) gene was suggested as a "DNA barcode" for species identification in eukaryotes (Hebert, Cywinska, Ball, \& DeWaard, 2003). The efficacy of DNA barcoding is based on the assumption that each sub-species will have small differences in barcoded sequences, representing intraspecific variability, whereas the genetic variation between the species exceeds the variation within species (Hebert et al., 2003). Unlike in DNA taxonomy, which helps in classification of both known and new species into their respective classification levels, DNA barcodes focus mostly on assigning unknown specimens to already ascribed species to enhance the discovery of new species. An example of such an identification system are based on COI genes, one that is particularly hard to define phenotypically (Tautz, Arctander, Minelli, Thomas, \& Vogler, 2003).

Multiple species of Moina such as Moina micrura, Moina brachiata, Moina macrocopa, and Moina weismanni have been identified phenotypically all over India, in regions like West Bengal, Nilgiri Hills, Bihar, Rajasthan, Bijapur, Kashmir, Meghalaya and Mandvi, etc (George Michael \& Sharma, 1988). Apart from India, these species have also been reported in diverse ecologies all over the world, such as Africa, Middle East Asia, South America, Europe and South East Asia (George Michael \& Sharma, 1988). Although phenotypic identification has been popular, molecular markers using both COI and ITS sequences have been recently reported to classify crustaceans (Pentinsaari et al., 2016). The primary requirement for most molecular studies is the method of DNA isolation, which employs either liquid nitrogen based abrasion of whole crustaceans, HotSHOT technique (Montero-Pau, Gómez, \& Muñoz, 2008) or less flexible kit-based techniques to extract DNA (Athanasio et al., 2016). These require specific handling equipment that come at a significant price. HotSHOT technique requires separation of mature ephippia from their mothers and decapsulation of diapausing eggs manually which in turn demands expertise. We wanted to design a cost-effective DNA extraction strategy by modifying existing methodologies, which would empower even undergraduate laboratories in India to carry out such characterization of small crustaceans. In this study, an unknown species of water flea was collected by Collaborative Undergraduate Biology Education (CUBE) student members in April 2012 from a freshwater tank at CHM (Smt. Chandibai Himathmal Mansukhani) College located in Ulhasnagar, Thane, near Mumbai $\left(19.22^{\circ} \mathrm{N} 73.15^{\circ} \mathrm{E}\right)$. It was later characterized as belonging to the genus Moina based on size and morphology by CUBE fellows at Acharya Narendra Dev College, Govindpuri, Delhi. This study presents morphological as well as molecular phylogenetic identification of this strain using the microgenomic system of identification that uses small segments of COI DNA and nuclear ribosomal internal transcribed spacer (ITS), to understand its phylogenetic origins.

\section{Materials and Methods}

Culture and growth conditions: The water-flea Moina obtained from Collaborative Undergraduate Biology Education (HBCSE-CUBE) were maintained in dechlorinated tap water either with algal feed, or by using drops of milk ( 2 drops milk per $500 \mathrm{ml}$ for normoxic healthy growth). It was optimized for parthenogenetic growth in $60 \mathrm{ml}$ batch cultures housed in $100 \mathrm{ml}$ glass tubes (with cotton plugs to allow exchange of gases) containing $80 \%$ of aerated autoclaved distilled water and $20 \%$ of spent media (from a previous culture of Moina). The organisms were maintained in ambient light: dark photoperiod and a temperature of about $26^{\circ} \mathrm{C} \pm 3^{\circ} \mathrm{C}$. Freshly prepared clear supernatants of powdered active dry yeast were used as feed at a final concentration of $3.6 \times 10^{4}$ cells $/ \mathrm{ml}$. The Moina macrocopa JSK1 populations seemed to plateau around a week and were harvested by filtering through a fine mesh/cloth and sub-cultured into fresh media on a weekly basis and used for morphological or molecular studies.

Genomic DNA Extraction: All chemicals used for DNA extraction were obtained from Merck (India), unless mentioned otherwise. For isolation of DNA, approximately $500 \mathrm{mg}$ wet weight of frozen tissue was collected by light trap method (Organs, 2017). Genomic DNA was extracted from Moina macrocopa JSK1, either by using the Insect DNA isolation kit (HiMedia, India) or by the Doyle and Doyle method which uses liquid nitrogen freezing prior to mechanical damage (Doyle, JJ; Doyle, 1990). We developed a modification of the Doyle and Doyle method wherein, the sample was crushed vigorously in a chilled mortar and pestle along with 1.2 gm of finely powdered porcelain for about $5 \mathrm{~min}$. Later, both sets were treated with slight modification to the Doyle and Doyle method as follows; the crushed tissue was resuspended in $500 \mu \mathrm{l}$ of modified lysis buffer (100 $\mathrm{mM}$ TrisCl pH 8, 2\% CTAB, $1.5 \mathrm{M} \mathrm{NaCl}, 20 \mathrm{mM}$ EDTA, $0.6 \%$ IGEPAL, $0,1 \%$ Sodium Deoxycholate and $0.2 \% \beta$ mercaptoethanol). The samples were incubated at $65^{\circ} \mathrm{C}$ for 45 minutes, following which, $500 \mu \mathrm{l}$ of freshly equilibrated (>pH 7.8) phenol: choloroform: isoamylalcohol ( $\mathrm{PCl}, 25: 24: 1$, procured from SRL Chemicals Ltd, India) was added and placed on a rotator (Trishul equipments, India) for 5 minutes. The samples were then centrifuged at $13,000 \mathrm{~g}$ for $10 \mathrm{~min}$. The supernatant was re-extracted with $\mathrm{PCl}$ followed by chloroform alone. Finally, sodium acetate $\mathrm{pH} 5.2$ was added to the supernatant (final concentration $0.3 \mathrm{M}$ ) followed by two volumes of chilled ethanol, and DNA was allowed to precipitate at $-20^{\circ} \mathrm{C}$ for $30 \mathrm{~min}$. The DNA pellet was collected at $13,000 \mathrm{~g}$ for $10 \mathrm{~min}$ and washed twice with ice-cold $70 \%$ ethanol. The final pellet was air dried and resuspended in nuclease free $10 \mathrm{mM}$ Tris $\mathrm{Cl}-1$ 
mM EDTA $\mathrm{pH}$ 8. The DNA samples were treated with RNAse $(50 \mu \mathrm{g} / \mathrm{ml})$ at $37^{\circ} \mathrm{C}$ for $1 \mathrm{~h}$ and stored at $-20^{\circ} \mathrm{C}$.

Molecular Analysis - Restriction digestion, ligation and PCR: To check the quality of extracted genomic DNA; restriction digestion, ligation and polymerase chain reaction was performed. The extracted DNA was digested with 2-3 units of EcoRI and HindIII (NEB, USA) per microgram of template, and incubated at $37^{\circ} \mathrm{C}$ for $1 \mathrm{~h}$ followed by heat inactivation at $65^{\circ} \mathrm{C}$ and $80^{\circ} \mathrm{C}$ respectively. The heat inactivated restricted DNA samples were ligated using 40 units T4 DNA Ligase (NEB, USA) per $200 \mathrm{ng}$ of DNA template and incubated at $16^{\circ} \mathrm{C}$ overnight. All samples were analysed on a $1.0 \%$ gel by electrophoresis in 0.5X TBE (Sambrook \& Russell, 2001) at 5-7 V/cm, using Lambda EcoRI-HindIII digest as a molecular weight reference (Thermo, India).

Polymerase chain reaction (PCR) was used to amplify a $648 \mathrm{bp}$ fragment of the 5 ' region of the COI gene using the primer pair jgHCO2198 (5'TAAACTTCAGGGTGACCAAAAAATCA-3') and jgLCO1490 (5'GGTCAACAAATCATAAAGATATTGG-3') (Folmer, Black, Hoeh, Lutz, \& Vrijenhoek, 1994). A 1,163bp fragment of the 5 ' region of Internal Transcribed Spacer (ITS) was amplified using primers ITS1 (5'TCCGTAGGTGAACCTGCGG-3') and ITS4 (5'TCCTCCGCTTATTGATATGC-3') (Perez, Abraira, Oster, Lespier, \& Vaamonde, 1975). Each reaction mixture consisted of 1X PCR buffer and 200 ?M dNTP (Takara), 5 ng of genomic DNA, 0.2 ?] $\mathrm{m}$ of each primer and 1 unit of Taq DNA polymerase (Takara). Amplification conditions: 1 cycle at $95^{\circ} \mathrm{C}$ for $3 \mathrm{~min}, 35$ cycles of denaturation at $95^{\circ} \mathrm{C}$ for $60 \mathrm{~s}$, annealing at $50^{\circ} \mathrm{C}$ (for COI) or $55^{\circ} \mathrm{C}$ (for ITS) for $30 \mathrm{~s}$ and extension at $72^{\circ} \mathrm{C}$ for $1: 30 \mathrm{~min}$, followed by $1 \mathrm{cycle}$ at $72^{\circ} \mathrm{C}$ for $7 \mathrm{~min}$. The amplicons were analyzed on a $1 \%$ agarose gel by electrophoresis in $0.5 \mathrm{X}$ TBE. The Lambda EcoRI-HindIII DNA ladder (Thermo, India) was used as reference for the estimation of the amplicon length. The PCR product was gel purified and sequenced by First Base, Malaysia.

Sequence analyses: (i) DNA alignment analysis: The $\mathrm{COI}$ and ITS gene sequences obtained by sequencing the PCR products, were imported in FASTA format, and used for BLAST search (nBLAST and pBLAST) and subsequently submitted to Genbank. The resulting BLAST sequences were either analysed pairwise or aligned using ClustalW in MEGA7 (sequences downloaded from Genbank). (ii) Phylogenetic analysis: A distance tree was created to study the ancestral and geographical relationship between various species. Sequences aligned using ClustalW were imported into MEGA7 and maximum likelihood distance tree of all the aligned sequences was created. (iii) Protein sequence analysis: A 216 amino acid sequence of the COI gene from Moina macrocopa JSK1 was imported in FASTA format along with those obtained by nucleotide BLAST, into MEGA7. Multiplesequence alignment was executed by ClustalW. Observed variations in the amino acid sequence of the conserved COI gene was studied and mapped on to the 3D structure of Bovine heart cytochrome c oxidase at the fully oxidized state (PDB 1V54) to assess plausible effects on the functionality of the protein.

\section{Results and Discussion}

Adult water-fleas obtained under our growth conditions were largely identified as parthenogenetic females (1-1.5 mm) carrying a brood pouch (size of brood varied from 4-8 neonates), and were larger than the occasional potential males (Benider, Tifnouti, \& Pourriot, 2002). Upon reaching higher population densities, Moina seemed to switch its 'mode of reproduction' to a sexual cycle, observed as increase in males and the appearance of sexual eggs (ephippium). To study classical daphnid anatomical features, we dissected the isolate and identified it as Moina for the following reasons; as shown in Figure 1, we observed the typical antennae, hairy carapace (about 40-45 hairs) and the abdominal hook. We also noted toothed setae on the terminal appendage of the first limb along with setae on the others, which pointed to a high likelihood of the species being Moina macrocopa (ElmoorLoureiro, Santangelo, Lopes, \& Bozelli, 2010; Rietzler, Maia-Barbosa, Ribeiro, \& Menendez, 2014). To further confirm our findings molecularly, we wanted to extract total genomic DNA and perform PCR-sequencing to compare well established DNA barcode sequences of two genetic loci, namely cytochrome $C$ oxidase subunit 1 (COI) and the nuclear ribosomal internal transcribed spacer region (ITS). Since to the best of our knowledge, this being the first Indian isolate to be molecularly characterized (as per exhaustive NCBI database searches), we wanted to acquire phylogenetic clues about the possible origins of this isolate.

Several reports have successfully reported genomic DNA extractions from crustaceans either by freezing the cells and grinding them in liquid nitrogen (Doyle, JJ; Doyle, 1990), or by using commercial insectDNA extraction kits (Athanasio et al., 2016). Having successfully tried both approaches to obtain PCR amplicons (data not shown), keeping in mind the main goal of CUBE education outreach; to generate research methodology that is both cost-effective and widely applicable at low-cost laboratory set-ups in India, we set out to simplify the extraction principle in order to avoid costly kits or difficult to store/handle reagents (i.e. liquid nitrogen). We tested mechanical abrasion as a tool, i.e. finely ground porcelain powder, to disrupt crustacean cells (as per Methods) and checked the efficacy of DNA extraction as well as quality thereof as shown in Figure 2. The ground porcelain obtained by manual grinding in a mortar pestle, broadly consisted of three size distributed populations of polygonal rough granules, as characterized by micrometry measurements; small -15 $\mu \mathrm{M}( \pm 3.9)$, medium - $30.4 \mu \mathrm{M}( \pm 6.8)$, and large $-42.8 \mu \mathrm{M}$ $( \pm 11.6)$ in length, with an occasional very large granule measuring around $100 \mu \mathrm{M}$ (Figure 2A). Whole Moina were ground in DNA extraction buffer along with porcelain powder using a mortar pestle cooled in a salt- 


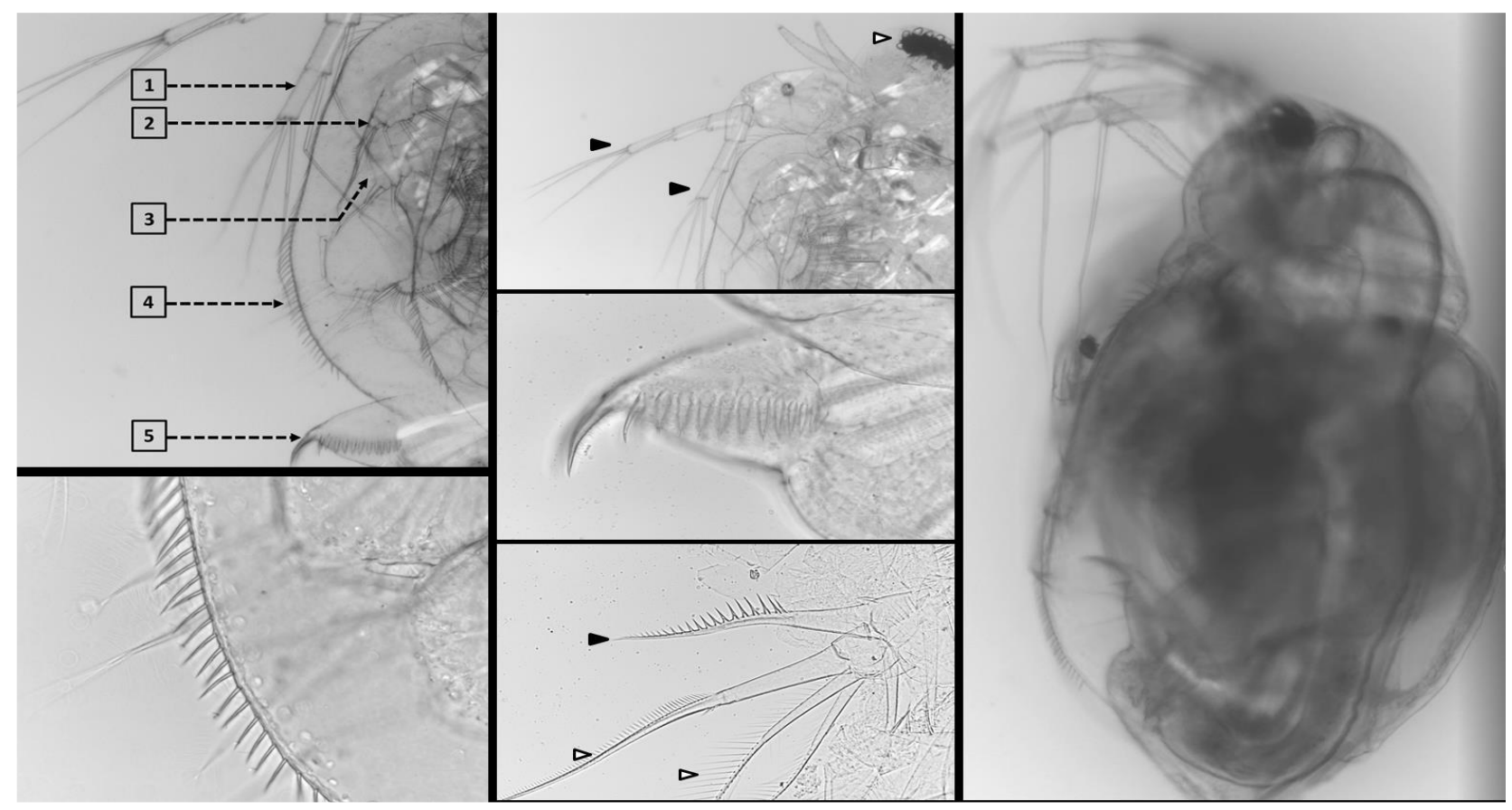

Figure 1: Morphological characterisation of the isolate. An individual Moina which had not yet reached sexual maturity, was dissected and observed under a light microscope; $[\mathrm{A}]$ represents part of the individual where the following anatomical parts were identified, namely $2^{\text {nd }}$ antennae (1), first appendage (2), $2^{\text {nd }}$ appendage (3), carapace with hair (4), and abdominal hook (5), at 10X. $[B]$ shows the two antennae (black arrows) and the eye of the individual (white arrow) at 10X. [C] Shows a higher magnification $(40 X)$ of the abdominal hook structure while [D] shows the identifying feature of species Moina macrocopa as per Elmoor-Loureiro et al, 2010: toothed setae on the terminal appendage of the first limb (black arrow) and setae on the other two appendages (white arrows) at 40X. [E] Arrangement of hairs on the carapace at 40X. [F] An entire live female Moina at 10X magnification.

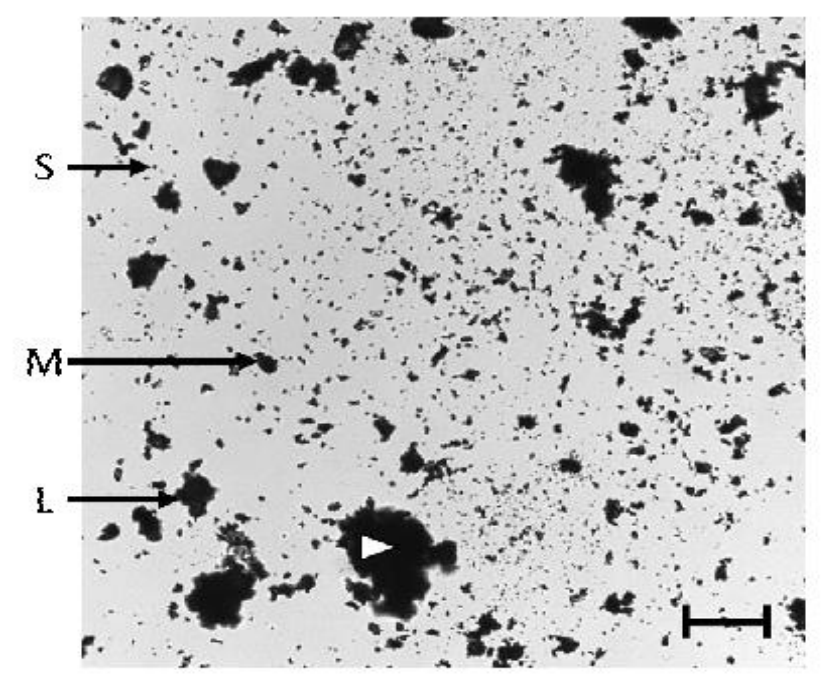

(A)

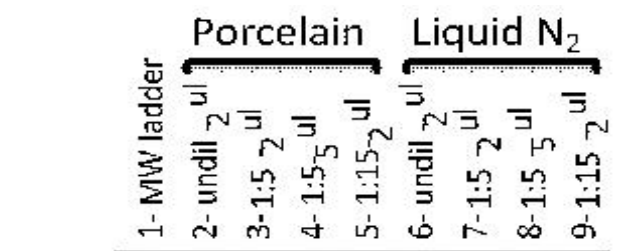

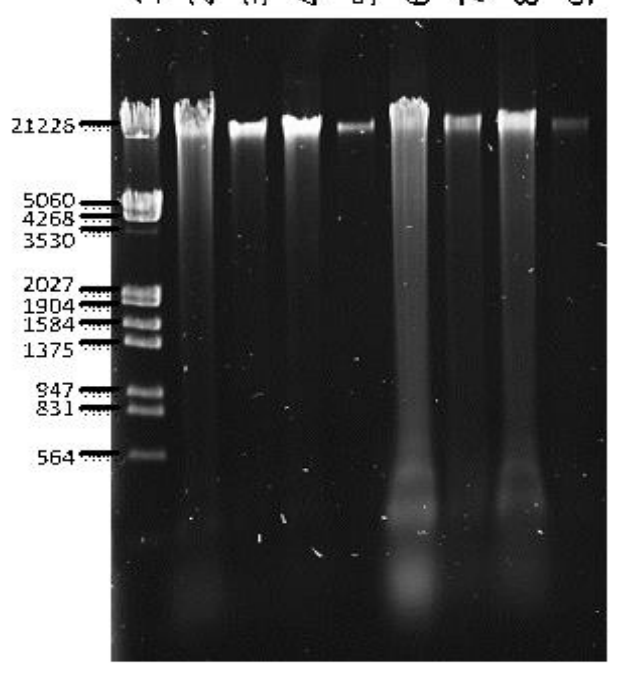

(B)

Figure 2: Genomic DNA extraction from M. macrocopa. [A] A representative sample of powdered porcelain viewed under a light microscope (20X magnification), where the scale bar denotes $100 \mu \mathrm{m}$. The arrows point to representative small (S), medium (M) and large (L) granules respectively, with an occasional very large piece in the field (white arrowhead) [B] Genomic DNA isolated by freeze fracturing whole individuals using liquid nitrogen by the standard method (lanes 6-9, Doyle, JJ; Doyle, 1990) was compared to porcelain powder abrasion method (without freezing, lanes $2-5$ ), by electrophoresis on a $0.8 \%$ agarose gel in $0.5 \mathrm{X}$ TBE. Several dilutions of the DNA were loaded to compare shear (observed in the overloaded undiluted lanes) as well as for quantitation (diluted lanes) using the lambda HindIII-EcoRI digest as molecular weight standard. 
ice freezing mixture. In comparison to the method by Doyle and Doyle (liquid $\mathrm{N}_{2}$, with some enhancements to the lysis buffer), we observed that cold mechanical abrasion with porcelain was not only successful, but showed a distinct improvement both in DNA quantity (compare dilutions in Figure 2B), as well as quality (some shearing of DNA in liquid $\mathrm{N}_{2}$ ). Measurement of DNA concentration against a Lambda EcoRI-HindIII digest as standard confirmed our findings. The yield of intact genomic DNA by the porcelain method $(266.2 \mathrm{ng} / \mathrm{ul})$ was more than two-fold than that of the liquid nitrogen abrasion methodology (104.7 ng/ul). In addition, we noted that our method gave good 260:280 UV absorbance ratio (1.82). Thus, we were successful not only in isolating intact genomic DNA from crustaceans without using costly kits or harmful reagents like liquid nitrogen, but demonstrated that home-grown porcelain powder based abrasion protocol can be executed with the help of moderate laboratory equipment and at a lower cost. In addition, since this method is not column based (akin to kits), it can accommodate higher amounts of DNA and can easily be scaled up.

In order to assess the quality of the extracted DNA for routine molecular biology use, we carried out a series of experiments. First we tested the restriction efficacy of DNA obtained by both methods, using EcoRI and HindIII enzymes. Figure 3A, lanes 1-4 indicate that the DNA obtained from porcelain abrasion was digestible by restriction enzymes similar to the method using liquid nitrogen (lanes 5-8). In fact, when tested for ligation, the DNA obtained from porcelain abrasion showed good efficiency, evident by the disappearance of the smear, as shown in Figure 3B. We even observed ligation products of very high molecular weight (smears indicated by the bracket shown in Figure 3B). Not presuming the species identity as $M$. macrocopa, we used universal primers designed for invertebrate phyla against the COI locus (Folmer et al., 1994) as well as primers designed for amplification of fungal internal transcribed spacer region (ITS) of the 5.8S rRNA locus (Perez et al., 1975). As shown in Figure 3C both PCRs yielded amplicons of the expected sizes, i.e. $1100 \mathrm{bp}$ for ITS and $\sim 709 \mathrm{bp}$ for COI. Here as well, we noted that the quantity of amplified DNA from the porcelain sample seemed higher, indicating better quality (as observed by the UV absorption 260:280 ratio which was 1.8 for different replicates). We gel purified the expected bands and sequenced it from both ends, to obtain two overlapping reads (1163 bp for ITS and 648 bp for COI), which were eventually submitted to GenBank (accession numbers COI - MH734122.1 and ITS - MH745035.1).

BLAST analyses of both $\mathrm{COI}$ and ITS sequence barcodes from the strain JSK1 used in the current study identified the species as Moina macrocopa, thereby confirming our phenotypic observations (Figure 4, Supplementary Data Table S1: ITS BLAST results and S2: COI BLAST results). The ITS sequence MH745035.1 from this study was the first reported Moina macrocopa sequence to be added to Genbank and it grouped with the two subsequently available ITS sequences for $M$. macrocopa of Chinese origin, and relatively distant to Moina mongolica, grouping it into a different clade (Figure 4A, Table S1). COI sequence BLAST analyses

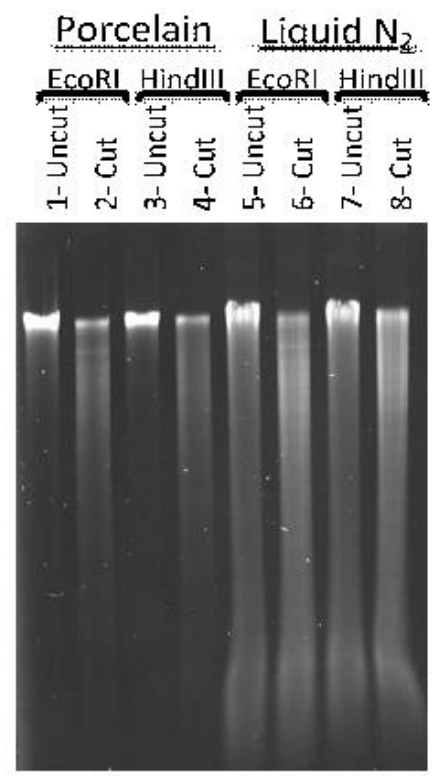

(A)

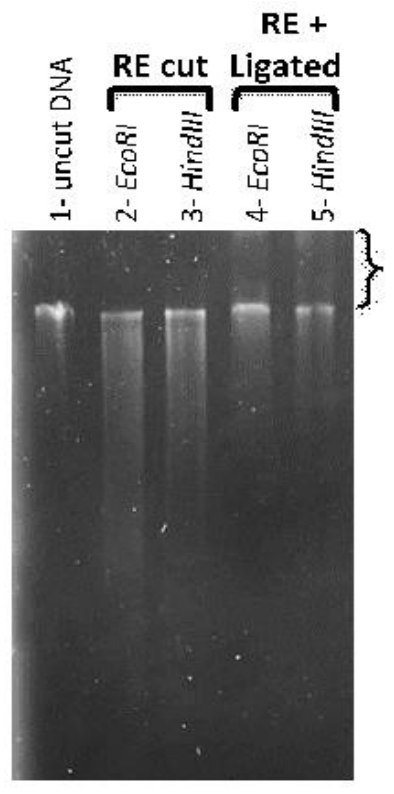

(B)

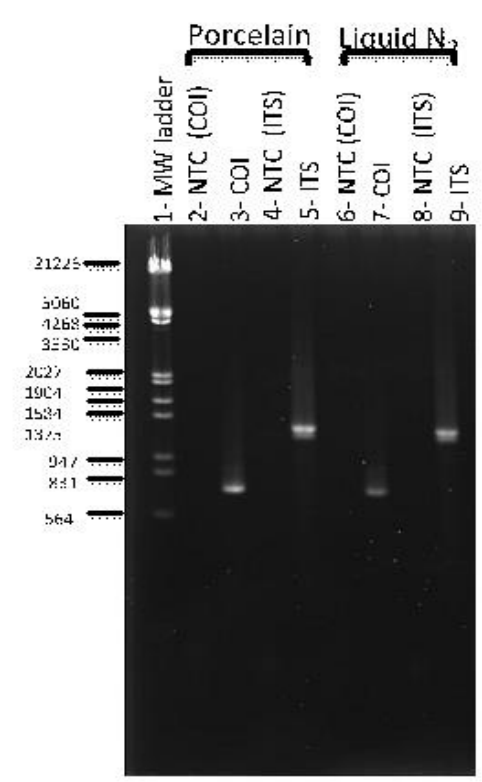

(C)

Figure 3: Molecular evaluation of DNA quality. Genomic DNA isolated was subject to three molecular characterizations for quality by $1 \%$ AGE; [A] DNA from both protocols (porcelain abrasion versus grinding in the presence of liquid nitrogen) were tested for restriction with either EcoRI or HindIII and compared with its corresponding uncut control. [B] the EcoRI or HindIII digested DNA from the porcelain samples (RE cut) were ligated with T4 DNA ligase at $16^{\circ} \mathrm{C}$ overnight (RE + ligated) and compared for ligation efficacy. [C] PCR for Cytochrome oxidase $1(\sim 700 \mathrm{bp})$ and ITS sequences ( 1,100 bp) genes was carried out using DNA from both protocols as templates and compared. 
revealed 42 Genbank reports from different strains of M. macrocopa belonging to geographically distinct regions such as North America, South America, and Eurasia (Supplementary Data Table S2). Unbiased phylogenetic trees built using MEGA7 revealed that the M. macrocopa group from the Americas (Mexico, Canada) formed a separate clade than the one from the Eurasian and Russian regions, reiterating recent haplotype reports (Montoliu-elena, Elías-gutiérrez, \& Silva-briano, 2019). Interestingly, although the only reported Chinese strain grouped with the American clade, the Indian strain JSK1 seemed to share homology with the Russian sub-clade (Figure 4B, indicated by a box), earlier identified as the Eastern Siberian-Far Eastern clade (Bekker, Karabanov, Galimov, \& Kotov, 2016). A separate group harbouring similarity between strains of Mexican and Hungarian origin, although diverse from the American group, seemed to club together into a separate clade, as was similarly revealed by Automatic Barcode Gap Discovery (ABGD) method as two genetic clusters (Makino, Machida, Okitsu, \& Usio, 2020). Since, this is the first Indian strain of Moina macrocopa to be sequenced for molecular phylogenetic classification, our study indicates a close relatedness to the Eastern Russian clade, and therefore opens up avenues for further query that can help trace an evolutionary or migratory relationship between these strains.
To uncover the variations and their functional role, the corresponding amino acid sequences from the 42 available COI genes of $M$. macrocopa strains (subset of Supplementary Data Table S2), were aligned by ClustalW multiple sequence alignment as shown in (Figure 5A) as well pairwise (pBLAST) to Moina macrocopa JSK1 and Bovine proteins as shown in (Supplementary Data Figure S1). The resulting variations were mapped onto the available Bovine crystal structure (Supplementary Data Figure S2, fully oxidized state, PDB 1V54_A) to evaluate its functional significance (Tsukihara et al., 2003). Multiple sequence alignment revealed two variations conserved across Moina species; one mapped to Leu 104 located in the transmembrane ?-helix of the Bovine complex (Figure 5B), corresponding to Leu 90 of Moina macrocopa (Figure S1); while the other, Met 176 mapped to the mitochondrial matrix domain (Figure 5B) corresponding to Met 162 in Moina (Figure S1). Although the latter region did show considerable variation around Met 162 , neither variation seemed to interact with any of the active-site residues of the Bovine structure (Figure S2) indicating minimal predictable effects on cytochrome oxidase activity.

\section{Conclusion}

We have developed a cost-effective methodology for DNA extraction from crustaceans, using porcelain
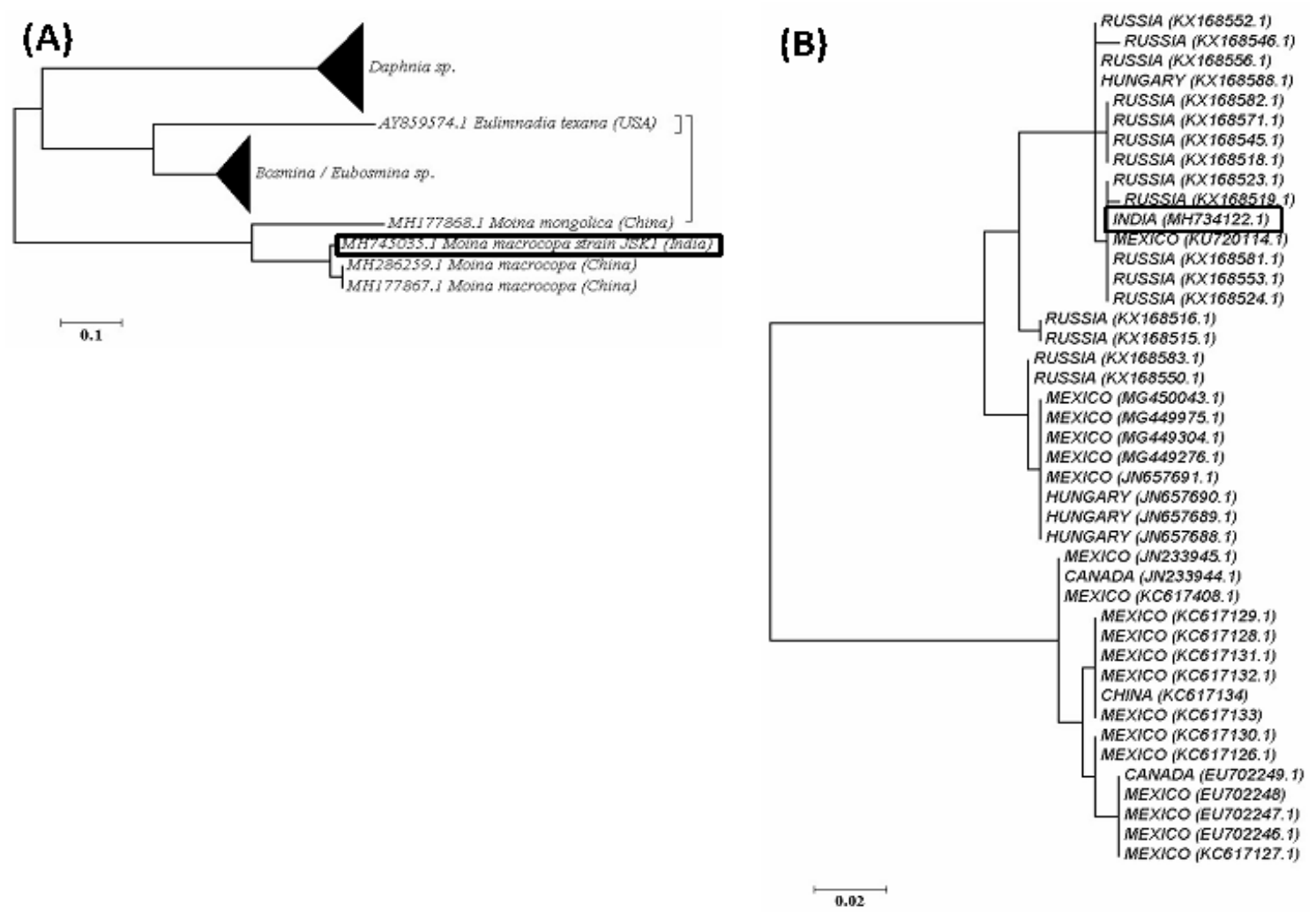

Figure 4: Phylogenetic analyses of DNA sequences. DNA sequences aligned using ClustalW were imported into MEGA7 and a maximum likelihood distance tree was created to study the ancestral and geographical relationship between the species. [A] ITS phylogenetic tree (sequences from Supplemental Table S1). [B] COI phylogenetic tree (sequences from Supplemental Table S2). The isolate from the current study is highlighted in a black box. 
(A)

IMDIA AYง 18800.1 MEXICO AVP 51690.1 NEXICO AVP 51628.1 MEXICO AVP 51026.1 NEXICO AVP51001. CABadA AEL16910.1 CMUAD AEL16909.1 NEXICO ACD 86280. MEXICO ACD86279.1 KEXICO ACD 86278.1 NEXICO ACD 86277.1 CHIMA AVR72707.i MEXICO AGL 10469.1 MEXXCO AGL10469.1 KEXICO AGL10468.1 KEXICO AGL 10466.1 MEXICO AGL 10465. MEXICO AGL 10464.1 vextco Act 10463. Kexco a.jel0463.1 uexico a xablo 462 . KEXICO AGL10461. NEXICO AGJ51535.1 MEXICO AE201689. HUDGARY AE201688, GONGARY AE201687.1 HONGARY AE201686.1 " R0S5I A0x13483. RUSS1A 20.13983. RUSSIA MOX13482. RUSSIA AOX13481.1 RUSSIA AOX13471. RUSSIA AOX13456. RUSSIA 20X13453.1 ROSSIR AOX13452.1 RessTh acos13450. RUSSIA AOX 13450. ROSSIA 20X13446. RUSSIA 20X13445. RUSSIA AOX 13424.1 ROSSIA $20 \times 13423$. RUSSIA MOX13419. RUSSTA AOX13418. RUSSIR 20X13416.

(B)

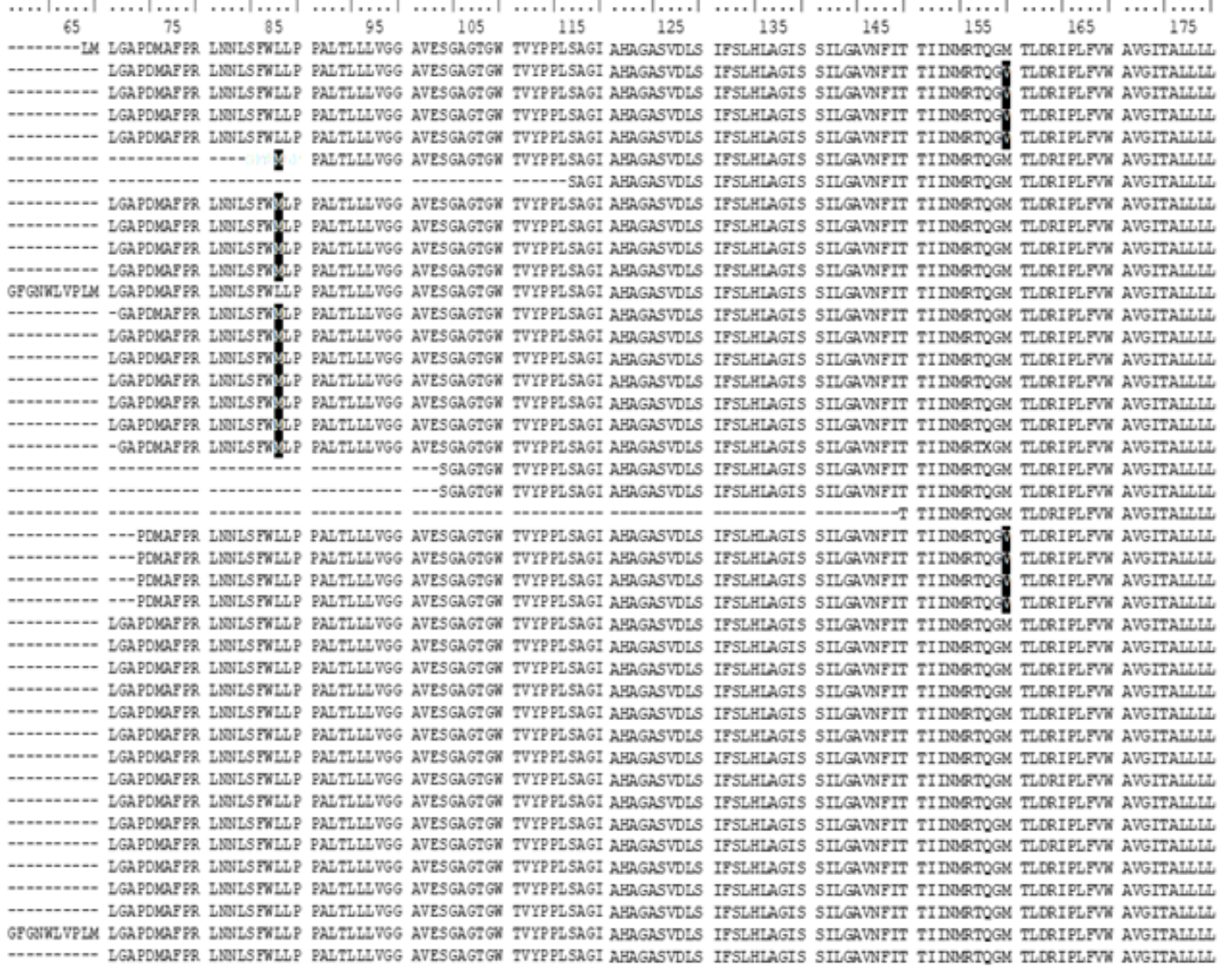

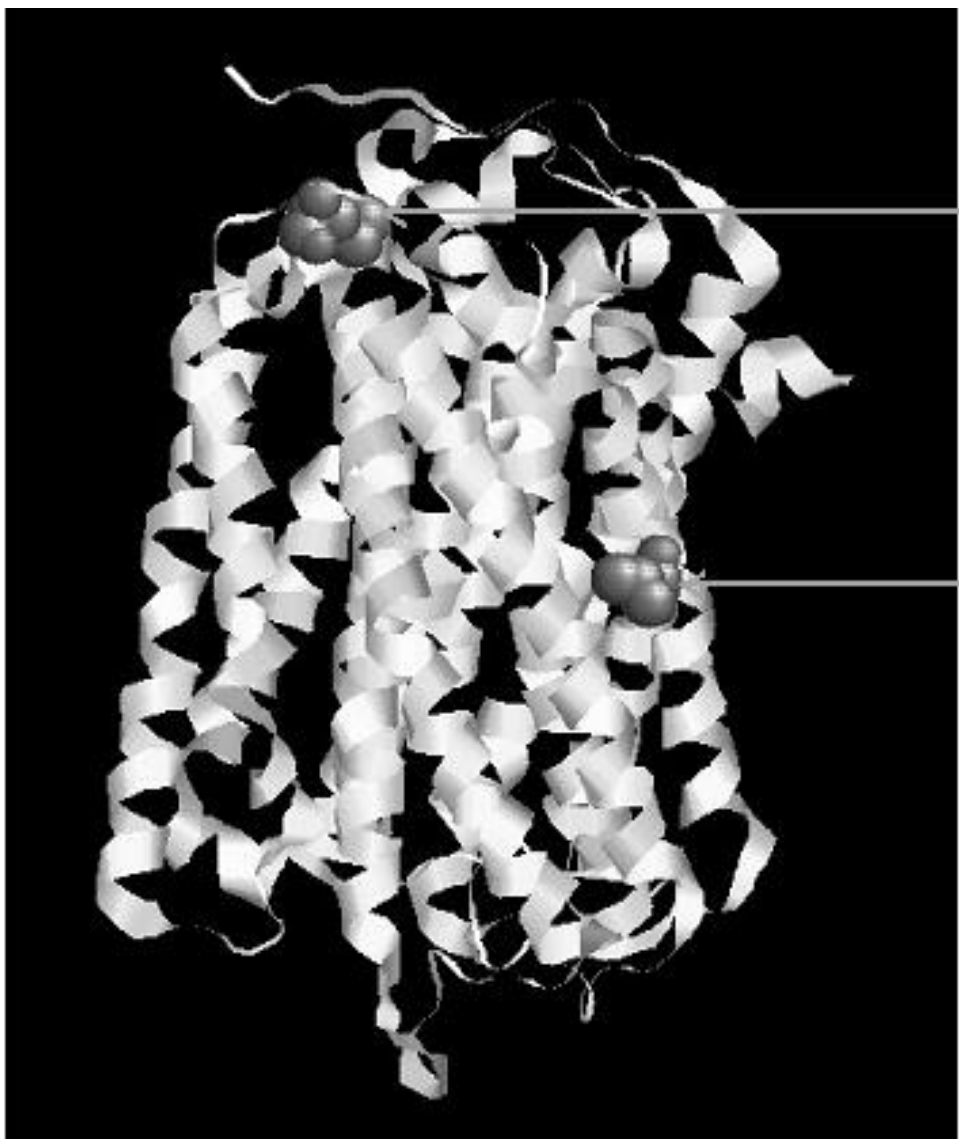

bLeแ 104

$\rightarrow$ mLẹ90

\section{bMet 176}

$\rightarrow$ mMet 162

Fig 5: COI protein sequence analyses. [A] ClustalW alignment of $42 \mathrm{COI}$ protein sequences (using Bioedit), to highlight the variations (in black) among the various geographical clades of Moina macrocopa (obtained from given accession numbers). [B] Mapping of the two amino acid variations (highlighted as space filled structures) onto the crystal structure of the Bovine COI chain A obtained from PDB (using RasMol v2.7.5). The amino acid positions are indicated as a prefix: ' $b$ ' for Bovine sequence and ' $m$ ' corresponding to Moina macrocopa JSK1. 
powder based abrasion, thereby avoiding liquid nitrogen handling (as largely reported and used). This methodology gave equivalent or better yields as per our analyses, and the DNA quality was good for restriction digestion, ligation, PCR as well as sequencing. Finally, barcode analyses of ITS 5.8S rRNA and COI gene helped molecularly classify strain JSK1 as Moina macrocopa which seems to harbor evolutionary relatedness with the Russian clade and not the North-American/Mexican clades.

\section{Ethical Statement}

The isolation, growth and characterisation of the water-flea Moina macrocopa was carried out in a BSL-1 facility, as Moina are not considered to be pathogenic. Since this study did not disturb environmental populations of water-flea nor use recombinant DNA technology to genetically engineer the organisms, ethical approval was not required. Handling and discard of all biological material were in tune with the institutional biosafety protocols as per UM-DAE CEBS/IBSC-1(2018).

\section{Funding Information}

This study was funded by support from the Department of Life Sciences, University of Mumbai and the Ramalingaswami Fellowship, Department of Biotechnology (D.O. NO BT/HRD/35/02/2006) India.

\section{Author Contribution}

JR conceived the study and collaborated with SS to execute it; SB, KK and SS contributed to Fig 1-3, SB and SS contributed to Fig $4 \& 5$, the manuscript was written by SS and edited by all the authors.

\section{Conflict of Interest}

The authors of the study have no conflicts of interest to declare.

\section{Acknowledgements}

We would like to thank Sameer Padhye for inputs during the study as well as $C$. Arunan, and Kajal Kumari of CUBE (HBCSE) for the isolate, and the students from different CUBE groups spread over Delhi and Mumbai for enthusiastically helping develop Moina as a model system.

\section{References}

Athanasio, C.G., Chipman, J.K., Viant, M.R., \& Mirbahai, L. (2016). Optimisation of DNA extraction from the crustacean Daphnia. PeerJ, 4, e2004. https://doi.org/10.7717/peerj.2004
Bekker, E.I., Karabanov, D.P., Galimov, Y.R., \& Kotov, A.A. (2016). DNA barcoding reveals high cryptic diversity in the north Eurasian Moina species (crustacea: Cladocera). PLOS ONE. https://doi.org/10.1371/journal.pone.0161737

Benider, A., Tifnouti, A., \& Pourriot, R. (2002). Growth of Moina macrocopa (Straus 1820) (Crustacea, Cladocera): Influence of trophic conditions, population density and temperature. Hydrobiologia, 468(Straus 1820), 1-11. https://doi.org/10.1023/A:1015214530485

Doyle, JJ; Doyle, J. (1990). Isolation of plant DNA from fresh tissue. Focus, 12(1), 13-15.

Elmoor-Loureiro, L., Santangelo, J., Lopes, P., \& Bozelli, R. (2010). A new report of Moina macrocopa (Straus, 1820) (Cladocera, Anomopoda) in South America. Brazilian Journal of Biology, 70(1), 225-226. https://doi.org/10.1590/s1519-69842010000100031

Folmer, O., Black, M., Hoeh, W., Lutz, R., \& Vrijenhoek, R. (1994). DNA primers for amplification of mitochondrial cytochrome c oxidase subunit I from diverse metazoan invertebrates. Molecular Marine Biology and Biotechnology, 3(5), 294-299.

George Michael, R., \& Sharma, B. K. (1988). Fauna of India and adjacent countries, 283.

Hebert, P.D.N., Cywinska, A., Ball, S.L., \& DeWaard, J.R. (2003). Biological identifications through DNA barcodes. Proceedings of the Royal Society B: Biological Sciences, 270(1512), 313-321. https://doi.org/10.1098/rspb.2002.2218

Makino, W., Machida, R.J., Okitsu, J., \& Usio, N. (2020). Underestimated species diversity and hidden habitat preference in Moina (Crustacea, Cladocera) revealed by integrative taxonomy. Hydrobiologia. https://doi.org/10.1007/s10750-019-04147-3

Mandal, S.C., \& Bhagabati, S. (2012). IMPORTANT LIVE FOOD ORGANISMS AND THEIR ROLE IN AQUACULTURE.

Montero-Pau, J., Gómez, A., \& Muñoz, J. (2008). Application of an inexpensive and high-throughput genomic DNA extraction method for the molecular ecology of zooplanktonic diapausing eggs. Limnology and Oceanography: Methods, 6(6), 218-222. https://doi.org/10.4319/lom.2008.6.218

Montoliu-elena, L., Elías-gutiérrez, M., \& Silva-briano, M. (2019). Moina macrocopa (Straus, 1820 ): a species complex of a common Cladocera, highlighted by morphology and DNA barcodes Moina macrocopa ( Straus , 1820 ): a species complex of a common Cladocera, highlighted by morphology and DNA barcodes, (January). https://doi.org/10.23818/limn.38.19

Organs, S. (2017). Nervous System and Sense Organs. Physiology of the Cladocera: Second Edition, 187-210. https://doi.org/10.1016/B978-0-12-805194-8.00013-1

Padhye, S.M., \& Dumont, H.J. (2014). Moina hemanti sp. nov., a new species of the genus Moina s.l. (Branchiopoda: Anomopoda) from Pune, India. Zootaxa, 3860(6), 561570. https://doi.org/10.11646/zootaxa.3860.6.4

Pentinsaari, M., Salmela, H., Mutanen, M., \& Roslin, T. (2016). Molecular evolution of a widely-adopted taxonomic marker (COI) across the animal tree of life. Scientific Reports, 6(March), 1-12. https://doi.org/10.1038/srep35275

Perez, G., Abraira, C., Oster, J.R., Lespier, L., \& Vaamonde, C.A. (1975). The effect of dexamethasone on urinary acidification. Proceedings of the Society for Experimental 
Biology and Medicine. Society for Experimental Biology and Medicine (New York, N.Y.).

Rietzler, A., Maia-Barbosa, P., Ribeiro, M., \& Menendez, R. (2014). On the first record of the exotic Moina macrocopa (Straus, 1820) in Minas Gerais State, Brazil. Brazilian Journal of Biology, 74(2), 518-520. https://doi.org/10.1590/1519-6984.14113

Sambrook, J., \& Russell, D.W. (2001). Molecular Cloning: A Laboratory Manual, Third Edition. In Molecular Cloning: a laboratory a manual.
Tautz, D., Arctander, P., Minelli, A., Thomas, R.H., \& Vogler, A.P. (2003). A plea for DNA taxonomy. Trends in Ecology \& Evolution, 18(2), 70-74. https://doi.org/10.1016/S0169-5347(02)00041-1

Tsukihara, T., Shimokata, K., Katayama, Y., Shimada, H., Muramoto, K., Aoyama, H., ... Yoshikawa, S. (2003). The low-spin heme of cytochrome $c$ oxidase as the driving element of the proton-pumping process. Proceedings of the National Academy of Sciences of the United States of America.

https://doi.org/10.1073/pnas.2635097100 